\title{
Cultura material e as conexões no \\ Mundo Grego
}

\section{Culture matérielle et connexions dans le Monde Grec}

\begin{abstract}
Ana Livia Bomfim Vieira*
Resumo: Este artigo tem como objetivo discutir as transformações que a perspectiva de história conectada trouxe para a área de Antiguidade. Além disso, objetivamos demonstrar como a expansão das pesquisas em Arqueologia, a partir do final do século $X X$, estimularam a compreensão da cultura material como intermediária nas relações de conexão e na construção de redes sociais no mundo grego.

Résumé: Ce travail a le but de discuter des transformations que la perspective de l'histoire connectée a apportées au domaine de l'Antiquité. En outre, nous visons à montrer comment l'expansion de la recherche en archéologie, à partir de la fin du XXe siècle, a stimulé la compréhension de la culture matérielle en tant qu'intermédiaire dans les relations de connexion et dans la construction de réseaux sociaux dans le monde grec.
\end{abstract}

Palavras-chave:

Histórias Conectadas. Cultura Material. Cultura Grega.

\section{Mots-clès:}

Histoires connectées. Culture matérielle.

Culture grecque.

\footnotetext{
* Professora adjunta do curso de História e do Programa de Pós-Graduação em História da Universidade Estadual do Maranhão. Coordenadora do Laboratório de História Antiga e Medieval do Maranhão (Mnemosyne).
} 
$\mathrm{N}$ este artigo, objetivamos discutir como a cultura material é fundamental não somente para a construção do conhecimento histórico sobre as chamadas sociedades "da Antiguidade", mas também porque tem contribuído para a pavimentação do caminho percorrido, e ainda em trânsito, pelo pesquisador de Antiguidade em direção ao campo das "histórias conectadas". O casamento entre a área e esse novo campo de observação não nos parece algo estranho, pois, para aqueles que lidam com a cultura material, sempre foi evidente que as interações, redes e conexões estavam lá, esperando que nos libertássemos dos eixos de análise espaço/tempo, restritos a certos elementos considerados como traços civilizatórios (MORALES; SILVA, 2020).

Estes traços (como, por exemplo, a democracia grega no Período Clássico ou o cristianismo romano) demarcavam o recorte temporal e espacial sobre os quais deveríamos nos debruçar acerca de dada sociedade da Antiguidade e evidenciavam o que Guarinello (2003, p. 53) chamou de uma "corrida de revezamento" de grandes feitos da Antiguidade, compreendidos como elementos formadores da cultura ocidental. Assim, a história das grandes civilizações da Antiguidade representava um projeto de genealogia europeia, organizando as macro-narrativas em uma linha de tempo explicativa de sua hegemonia.

Estas macro-narrativas eurocêntricas, que dominaram a historiografia nos séculos XIX e XX e que estabeleceram a linearidade temporal como eixo central na construção de uma etapa da história da humanidade, são, nos dias atuais, quase que de forma unânime, criticadas pelos historiadores da área. A periodização "didaticamente" produzida com a intenção de explicar como as sociedades da Antiguidade contribuíram para o desenvolvimento da "Civilização" é também percebida pelos pesquisadores como fator que mais confunde do que contribui para a compreensão dessas sociedades.

As críticas e a consequente crise das narrativas eurocêntricas do final no século XX, provocada pela perda da hegemonia dos impérios europeus associada à explosão das lutas identitárias por direitos civis e anticoloniais (MORALES; SILVA, 2020), acertaram em cheio os estudos sobre o Mundo Antigo. As pesquisas foram deslocando-se em direção a uma mudança de paradigma que promoveu uma importantíssima desnaturalização da tradicional escrita da História Antiga (ÁVILA 2016; YOUNG, 2004). De modo geral, o trabalho de investigação sobre a Antiguidade passou a olhar para aqueles períodos das "histórias das sociedades antigas" que havia ficado em um limbo, por não poderem ser associados à trajetória histórica da "grandiosidade europeia".

Outros espaços também passaram a ser foco de atenção e preocupação dos pesquisadores, e com isso vamos observar, por exemplo, o crescimento de investigações sobre os povos africanos e suas conexões com os gregos (BERNAL, 1987; ROGERS; LEFKOWITZ, 1996) ou acerca dos impérios médio-orientais, não necessariamente quando 
suas histórias se cruzam às de gregos e romanos em seu "auge". De fato, o eurocentrismo e a produção de uma "Antiguidade comum" ao mundo fizeram com que ele mesmo passasse a ser objeto de investigação a partir de pesquisas sobre a recepção dos clássicos pela Modernidade (SILVA, 2007). Quer dizer, a crítica e desconstrução de noções "fetiche" como 'nação', 'civilização', 'império' ou mesmo a das 'origens' marcaram profundamente os estudos em Antiguidade.

Para o objetivo deste trabalho, precisamos ainda mencionar o papel importante da renovação na historiografia do final dos anos 1990. Foi incorporada às preocupações com a dimensão política e econômica, estudos culturais relacionados às múltiplas dimensões das sociedades humanas e, nesse bojo, a História Antiga não ficou para trás.

Os anos finais do século XX, na verdade, foram decisivos para as mudanças de paradigma na compreensão da Antiguidade também do ponto de vista arqueológico. Foi um período em que as pesquisas arqueológicas das sociedades da Antiguidade ganharam importância e dimensão, provocando um grande número de estudos e intensificando as fontes disponíveis para os historiadores. Diante de um conjunto tão amplo e diverso de testemunhos materiais sobre as culturas do Mundo Antigo, foram rompidas definitivamente as ligações com as explicações de perspectivas nacionalistas e endógenas. Assim, a perspectiva descolonial e crítica da historiografia eurocêntrica e o crescimento da importância sobre os estudos culturais ganharam reforços com a intensificação do conhecimento da cultura material das sociedades da Antiguidade, o que tornou evidente a impossibilidade de abordarmos esses grupos de forma isolada.

A publicação do The corrupting sea, de Nicholas Purcell e Peregrine Horden (2000), autores bastante influenciados pela obra impactante de Fernand Braudel (1949 [1983]), O Mediterrâneo e o mundo mediterrâneo na época de Filipe II, contribuiu para transformar o Mediterrâneo em espaço central das investigações. O Mediterrâneo integrado, de fronteiras fluidas e sujeitos móveis, foi descrito pelos autores na longa duração a partir de uma história ecológica da região. Para os autores, era um mar amigável, próprio, em boa parte do ano, à navegação. E esse é um ponto central na análise dos autores sobre o papel fulcral que o Mediterrâneo desempenhou na conexão entre as sociedades. Apesar das críticas que a obra recebeu pela ruptura com a questão da temporalidade e certa perspectiva de "mundo sem fronteiras", de conexões longas e duradouras, para a historiografia sobre a Antiguidade, as interações entre as sociedades nunca mais foi vista da mesma maneira. O Mediterrâneo deixou de ser apenas um cenário, um espaço de trânsito, para assumir um protagonismo em uma história que integrava o ambiente aos grupos sociais. 
A fluidez excessiva das fronteiras também foi algo bastante criticado nessa perspectiva de Purcell e Horden sobre o Mediterrâneo (MALKIN, 2005). No entanto, os pesquisadores não podiam mais deixar de olhar para o chamado Mundo Antigo de forma integrada. Os níveis, intensidades e formas dessas integrações, com suas retrações ao longo do tempo, é que começaram a ser historicizados. Sobre esse aspecto, vale destacar a publicação de Small Greek word: networks in the ancient Mediterranean, de Irad Malkin (2011). A obra de Malkin historiciza os processos de integração, na medida em que diferencia a forma como essas redes foram construídas. Para Malkin, redes descentralizadas construíram o mundo grego, projetando uma "identidade" grega reforçada, sobretudo, pela distância da Hélade.

A obra de Cyprian Broodbank (2013), The making of the Middle Sea, a history of the Mediterranean from the begining to the emergence of the Classical world, mais ainda que a de Malkin, busca historicizar as redes de integração e comunicação e suas mudanças ao longo do tempo. Estudando as interações costeiras, o autor apresenta os múltiplos sujeitos que se tornaram agentes importantes nos processos de integração/retração em torno do Mediterrâneo. Para Broodbank (2013), comerciantes, soldados, sacerdotes, viajantes, colonizadores, entre outros, são os "tecelões" destas redes sociais. Assim, é possível olhar para a história da Antiguidade de uma forma completamente nova. Compreender as interações e conexões é parte importante da compreensão do Mundo Antigo.

Historicizar os processos de integração passa, também, por rever conceitos tidos como consolidados, já muito bem definidos. Morales (2010) aponta, por exemplo, para a crítica necessária ao conceito de pólis, a partir da pólis de Atenas tida como modelo padrão. Contudo, sabemos que tanto Atenas como Esparta, as póleis mais conhecidas da Grécia, não eram nem de longe modelos comuns. $O$ autor parte da figura do meteco para apontar vários modelos de póleis descritas pela historiografia e todas baseadas em Atenas. A figura do meteco se torna, assim compreendemos, ainda mais importante nessa avaliação, pois ele é um elemento que vem de fora. Como estrangeiro, estaria excluído da vida pública e religiosa da pólis. Contudo, a presença e permanência desses sujeitos em Atenas, ocupando lugar na economia e na vida cotidiana da cidade (ANDRADE, 2002), sugere uma participação e integração muito mais efetiva. A ideia do estrangeiro como excluído, como sujeito a-político, não se sustenta se considerarmos o mundo grego e a pólis ateniense como integrada às redes do Mediterrâneo.

Estes estrangeiros, muitas vezes comerciantes ou artesãos, agiam como parte ativa das redes de comunicação. Para entendê-las, as investigações precisam lançar mão, sobretudo, da documentação material. Grande parte das evidências destes processos estão sob a forma de casas, templos, esculturas, ânforas, vasos de cerâmica decorados, objetos 
do cotidiano e outros. Como já mencionado, sem dúvida, a ampliação das pesquisas arqueológicas fomentou a concepção de uma Antiguidade muito mais integrada do que os historiadores imaginavam. E é a documentação arqueológica, material, que se torna imprescindível na busca pelos fios dessas redes. São arqueólogos que, em 2013, publicam um manifesto defendendo a utilização da teoria das redes, sobretudo para o comércio mediterrâneo. ${ }^{1}$

O arqueólogo Knappett (2011) reforça o aspecto prioritariamente material das redes de interação. Ele chama a atenção para o fato de que historiadores, muitas vezes, deixam para trás a materialidade resultante das interações, muito embora essas sejam fundamentais como elementos de compreensão destes processos. As sociedades, portanto, não são concebidas como cenários onde se desenrolam as ações sociais, e sim como um encadeamento, um entrelaçamento de pessoas e objetos. Os objetos são, assim, conectores fundamentais de que o estudo nos permite identificar e compreender as interações permanentes, mas também aquelas de carater momentâneo ou, ainda, os movimentos de expansão e retração das interações.

Figura 1 - Costa mediterrânea: colônias e metrópoles gregas

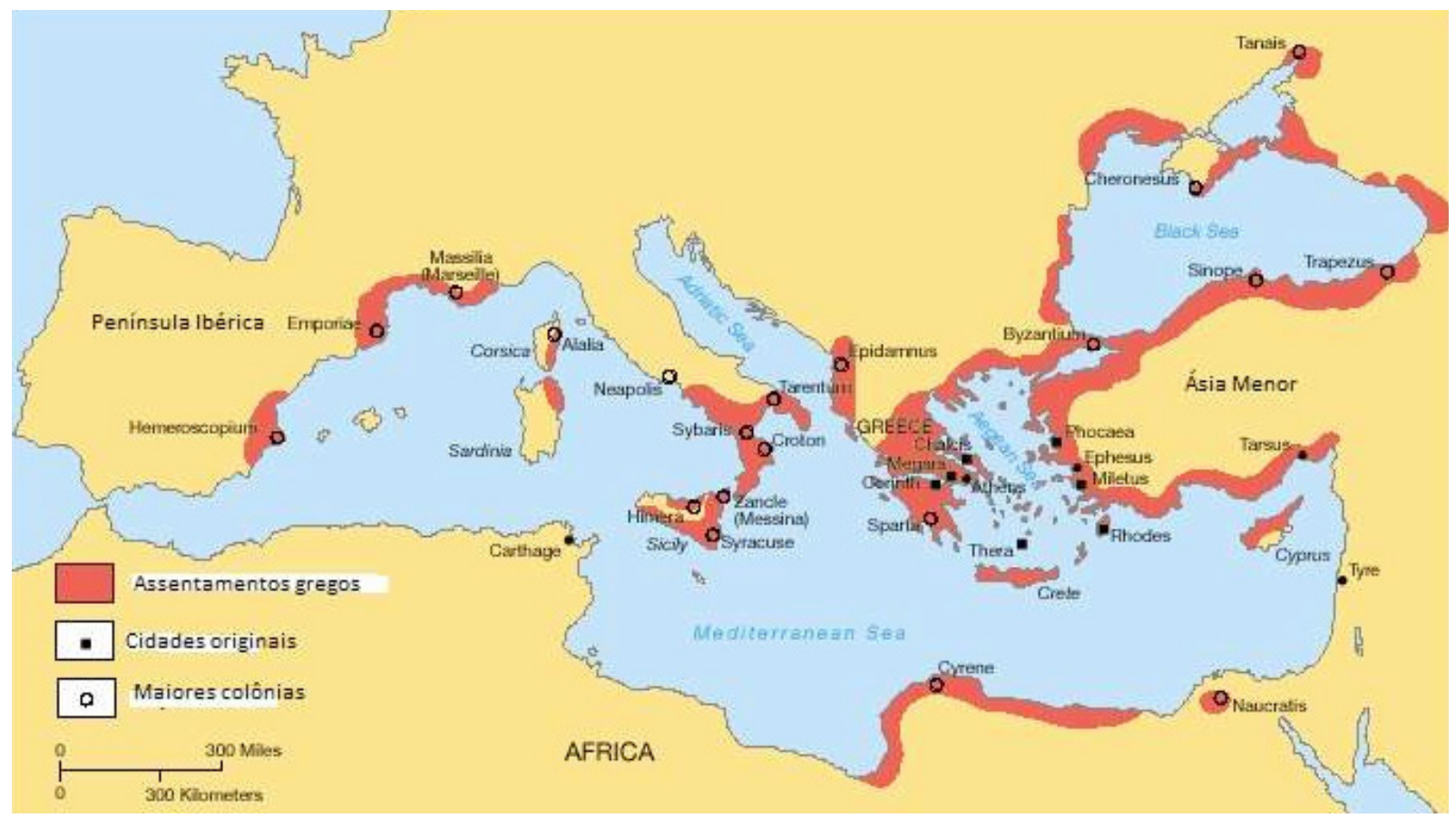

Fonte: <https://commons.wikimedia.org/wikiFile:Coloniza\%C3\%A7\%C3\%A3ogrega.jpg>. Acesso em: 26 mai. 2020.

\footnotetext{
${ }^{1}$ Este manifesto intencionava, principalmente, atrair pesquisadores que se interessavam por outros objetos, para a utilização da teoria das redes. Podemos acessar as premissas deste manifesto em: <http://journal.antiquity.ac.uk/ projgall/leidwanger342>. Acesso em: 27 jun. 2020.
} 
Foram esses movimentos que formaram o "pequeno mundo grego" de Malkin (2011). Entre os séculos VIII e VI a.C., uma rede de "nós" formou a cultura grega. Por esses nós eram transmitidas mensagens e informações que construíram uma identidade helênica, apesar das distâncias e dispersão.

Foi por meio das águas que os gregos migraram, fundaram novas cidades, criando identidades regionais e transferindo cultos, mitos, convenções artísticas e artefatos, ânforas e filosofias. Links, tanto planejados quanto fortuitos, rapidamente reduziram a distância entre os nós da rede, tornando o vasto Mediterrâneo e o Mar Negro um small world [pequeno mundo], um termo definidor na corrente teoria das redes. Essas redes informavam, algumas vezes criaram, e mesmo vieram a expressar o que chamamos de civilização grega (MALKIN, 2011, p. 5).

Para o autor, a cultura grega começa a se formar exatamente a partir da dispersão grega pelo Mediterrâneo. A Hélade, portanto, foi formada por intermédio da conectividade entre cidades, em redes de múltiplas extensões. Eram relacionadas a partir de compartilhamento de comércio, religião e cultura. Nessas redes, os objetos eram mediadores e integradores. Podemos remarcar a questão da circulação dos vasos gregos de cerâmica.

Uma investigação que tem como corpus documental os vasos e leva em consideração o aspecto da circulação e sua característica de mediação não consegue ficar limitada ao campo da História Cultural, por exemplo. A circulação dos vasos empurra a investigação para outros campos, como o político, o econômico e o das relações sociais. As cerâmicas ática e coríntia circularam e se difundiram pelo Mediterrâneo, conquistando o mercado etrusco (LIMA, 2011). Os vasos áticos e coríntios representaram objetos de integração econômica, evidenciando as conexões entre regiôes do Mediterrâneo.

Como dissemos, todavia, o estudo dos vasos ultrapassa os limites de uma história econômica. Muitos desses vasos exportados eram suporte de representações imagéticas que comunicavam uma mensagem e eram, ao mesmo tempo, lidas pelos seus receptores. No caso das cerâmicas áticas, por exemplo, é posível apreender como os etruscos incorporaram a figura de Héracles, o herói grego. Segundo Camporeale (1997), Héracles fazia parte do imaginário heroico da aristocracia etrusca, o que se deu por meio da interação da Etrúria com a Hélade através da importação dos vasos de cerâmica. 
Figura 2 - A costa mediterrânea

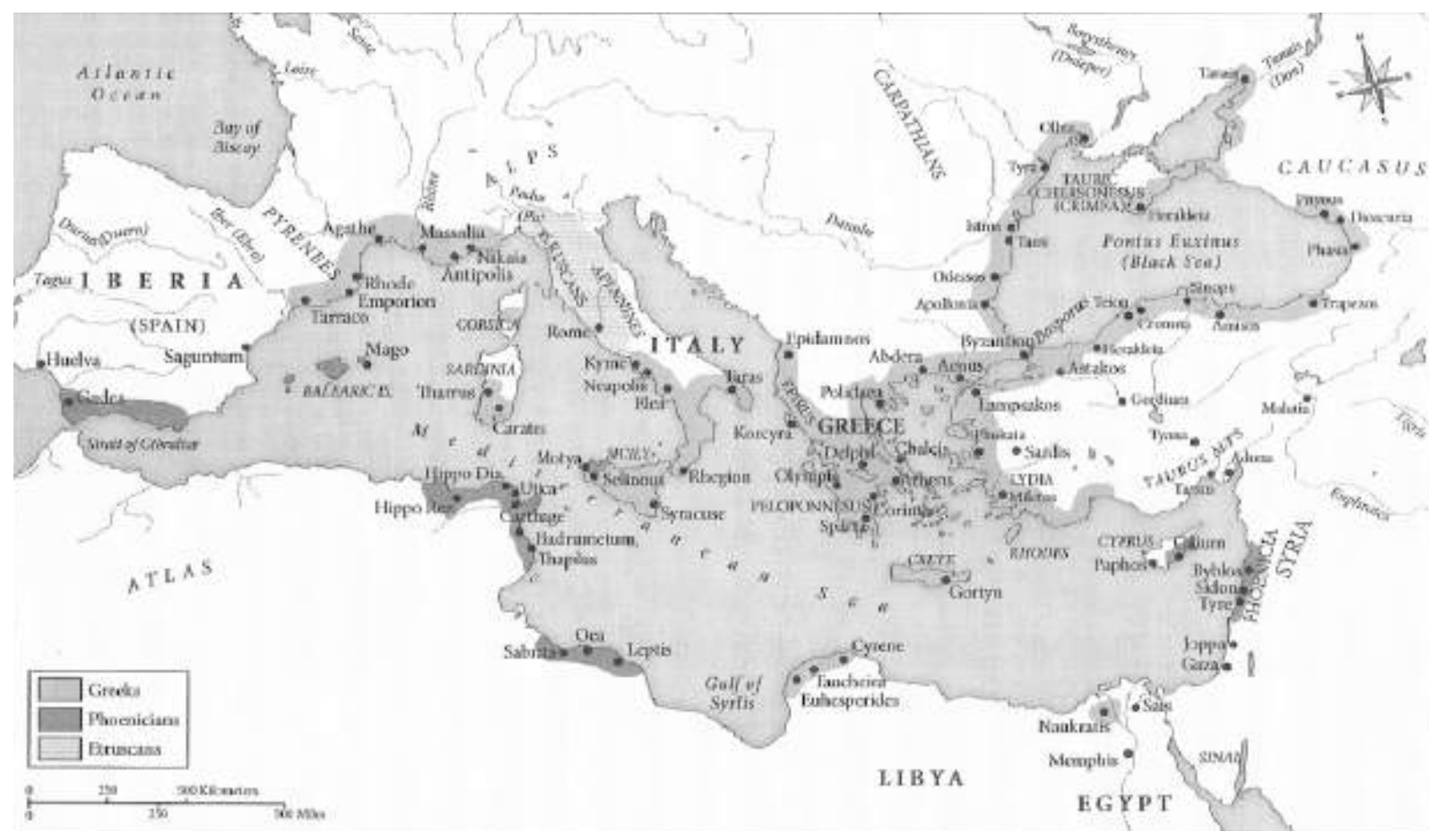

Fonte: Malkin (2011, p. 4).

Sabemos que a navegação, o comércio e os processos de colonização, importantes agentes de conexão, permitiram a circulação tanto das cerâmicas como dos artesãos por toda a costa mediterrânea. Suas criações se espalharam, integrando simbolicamente culturas dispersas pelo Mediterrâneo e, ao mesmo tempo, contribuindo para a construção de uma identidade helênica, para além das questões territoriais, como expõe Malkin (2011).

Essa dispersão dos vasos pelo Mediterrâneo suscita, portanto, a questão da importância da cultura material nos estudos das conexões no mundo grego. Esses objetos e, em especial, os vasos de cerâmica áticos e coríntos, ainda levavam consigo as imagem, representando crenças, valores, costumes, tradições e memórias para muito além do próprio mundo grego. Nessa direção, fica evidente que sua dispersão e circulação pelo Mediterrâneo apresenta aos historiadores a oportunidade de perceber as diferentes leituras e interpretações que as imagens pintadas nos vasos provocam em diferentes receptores. Uma mesma cena seria interpretada de formas diferentes:

Um heleno poderia usar uma cratera em um contexto ritual, de festa, durante um sympósion. Já um etrusco a usaria para decorar a tumba de um ilustre membro de sua comunidade. A representação de uma cena de kômos em um vaso significava, para um heleno, uma procissão masculina catártica. Contudo, para um etrusco, poderia significar uma alegre procissão familiar, entre pais e filhos (LIMA, 2011, p. 39). 
Podemos dizer que os atenienses contavam histórias sobre eles mesmos por meio das imagens pictóricas. Com elas, teceram uma rede complexa da cultura helênica, retomada a partir dos estudos de conectividade. Desse modo, esta sociedade nos deixou artefatos diversos, como esculturas, esquemas variados de composição arquitetônica, imagens em suporte cerâmico e uma variedade de objetos de uso cotidiano, que permitem ao historiador levantar problemas em relação aos valores, às práticas, às tensões e aos conflitos sociais próprios da estrutura políade e como essas mensagens foram apreendidas para além do mundo helênico.

A imagem restitui ao olhar a eclosão do visível. A imagem torna sensível a presença do ausente e provoca um relacionamento entre nós e o que é representado. A matéria da imagem se dá por grau de percepção, mas de um só golpe. Pela imagem, nós somos duplamente reconduzidos ao real. De um lado, porque a representação traz a marca da insuficiência em relação à realidade; ela reforça o desejo de se reencontrar efetivamente com o mundo. De outro lado, a imagem possui o poder de transformar a realidade material. Ela é capaz de produzir um sentimento que conduzirá a uma ação no mundo material. E essa ação modifica o real, reelabora valores e integra culturas.

A imagem é um constante jogo ou tensão entre a presença e a ausência da coisa (LAVAUD, 1999). Pode-se se dizer que a imagem apresenta a forma a posteriori do espaço. O que a imagem traz ao olhar não é nem o dado sensível, já espacialmente organizado, nem a forma pura, a priori, do espaço, mas a maneira de se reconhecer e se elaborar este dado. Desta forma, a cultura helênica foi, nas redes de conexão, reelaborada pelas culturas do Mediterrâneo e pelos próprios gregos das colônias.

As imagens passam uma mensagem lúdica e, portanto, possuem códigos de representação e de leitura. Uma imagem e seus códigos estariam ligados a um momento. Os vasos áticos, por exemplo, mesmo quando eram destinados à exportação, serviam como suporte para representações dos valores e costumes gregos. Mas como estas representações nunca são o real, elas são uma obra aberta, permitindo que aqueles que entram em contato com a mensagem, a compreendam e a incorporem a partir de conexões que terão sentido para aquele receptor, naquela cultura. A imagem é uma forma de linguagem específica. Ela não busca representar o real, e sim dar sentido ao real (SCHNAPP, 1994-1995).

Os pintores dos vasos (sejam eles cidadãos - eleutheroí -, estrangeiros domiciliados - metecoi - ou escravos - douloí), vivem em Atenas, conhecem os saberes que circulam e a pluralidade cultural interna; estão submetidos às mesmas normas e vivenciam as tensões e conflitos de forma coerente aos seus lugares na hierarquia social. Representam estes conflitos e valores nas imagens pictóricas dos vasos. Por outro lado, o que os artesãos e 
pintores produzem também está impregnado de aspectos daqueles grupos culturais que irão receber os objetos.

Esta dinâmica de representação, onde eu me represento ao mesmo tempo em que estou produzindo uma mensagem que desejo que seja entendida e apreendida pelo outro, só é possível em processos de integração e conexão. A partir desses conhecimentos é que autores importantes propuseram pressupostos para a análise das imagens em suporte de cerâmica, valendo a pena destacá-los aqui:

10. Levantar o corpus imagético, de acordo com a temática problematizada, observando todas as imagens pintadas nos vasos selecionados. Ou seja, o ideal é que tenhamos toda a superfície de cada vaso e as imagens nela pintadas. Isto porque o pintor cria o tema/mensagem de forma global e de acordo com a forma da superfície e dos esquemas de composição conhecidos que dispõe para executar o desenho. Fica claro, portanto, que não se pode iniciar a leitura sem que: a) se tenham todas as imagens da superfície do vaso; b) se conheça a forma do vaso e seu uso social; c) se obtenha o lugar em que foi encontrado, a data provável do vaso, onde foi produzido, se, possível, quem produziu, onde e quem o pintou, e se existem inscrições no vaso e o que significam. Estes dados, por exemplo, demonstram as redes de comércio e difusão cultural e ajudam nas possíveis leituras das imagens, inclusive a respeito das intenções do pintor; d) se observe a pintura (figuras negras ou figuras vermelhas) e o esquema de composição das imagens.

$\mathbf{2}^{\mathbf{0}}$ - Os vasos de cerâmica acompanhavam o grego desde o nascimento, casamento até a morte; da casa à ágora, dos lazeres aos ritos públicos, portanto, as imagens dos vasos tiveram uma ampla circulação no interior da Grécia. Logo, as redes e conexões dentro do mundo grego são também importantes eixos de análise a partir da cultura material. Como já lembrado, as póleis não foram homogêneas. Por que o padrão de consumo dos vasos seria?

$3^{\circ}$ - As imagens são olhadas e compreendidas de forma sincrônica, global e imediata, diferentemente da escrita, que poderíamos chamar de diacrônica, visto que implica um olhar direcionado temporalmente e espacialmente e muitas vezes lida em voz alta para que se fosse entendido o seu significado. É de nosso conhecimento que a sociedade políade se estruturou como uma comunidade do ver e do ouvir, isto significa dizer que tradição e memória indicavam as formas de pensar, representar, criar e falar de si próprio e dos outros; o ver estava diretamente ligado ao saber. Assim, as representações imagéticas dos suportes de cerâmica são fontes importantes para apreender como cada cultura se via e gostaria de se representar para o exterior e, da mesma forma, representava os outros a partir de concepções ligadas à sua própria cultura e tradições; 
$4^{\circ}$ - Para se compreender o sentido das mensagens que circulavam, é preciso que se conheça a sociedade, sua cultura e seus códigos de linguagem. Sendo assim, o historiador da Antiguidade precisa conhecer as imagens produzidas nos vasos e em outros suportes, como: pedra, mármore e metais, para que possa se familiarizar com os signos, suas combinações e os seus significados, ou seja, compreender os diferentes códigos de leitura das imagens, gestos, vestuário, mobiliário e monumentos. Conhecer estes signos e significados é fundamental para, também, conseguir elaborar as comparações entre culturas diferentes que têm, no objeto, um nó da rede de conexões.

É claro que não só de vasos de cerâmica vivem as redes de conexão. A cultura material é muito mais que isso. Mas, a partir da compreensão do papel do comércio e exportação de vasos de cerâmica, acreditamos que seja possível entender como a cultura material tem lugar privilegiado na construção de uma nova história do mundo grego a partir de suas conexões.

\section{Considerações finais}

A história da Antiguidade já não é mais a mesma. Rompeu com antigos paradigmas que a localizavam em uma linha temporal, de caráter genealógico, em bloco composto de recortes de tempo/espaço dispersos, mas que por várias razões eram considerados formadores da civilização ocidental, leia-se, europeia. A História Antiga tradicional era a História Antiga da humanidade.

As renovações pelas quais a área passou, desde fins do século XX, proporcionaram uma retomada dos estudos em Antiguidade sob novas perspectivas, muito mais interessantes. A ampliação das pesquisas arqueológicas evidenciou a necessidade de observar e aprofundar as conexões entre as regiões do Mediterrâneo e até entre uma mesma cultura, como é o caso grego, uma sociedade dispersa por extenso território. Assim, a cultura material toma lugar de destaque nas pesquisas em história da Antiguidade por ser identificada como intermediária das relações de conexão/interação e formação de redes.

Compreender a cultura grega como tendo sido construída nessas e dessas interações nos ajuda a colocar em perspectiva não só os processos que constroem as identidades sociais, mas também os elementos que produzem as diferenças. 


\section{Referências}

ANDRADE, M. M. A vida comum: espaço, cotidiano e cidade na Atenas Clássica. Rio de Janeiro: DP\&A, 2002.

ÁVILA, A. L. Povoando o presente de fantasmas: feridas históricas, passados presentes e as políticas do tempo de uma disciplina. Revista Expedições: Teoria da História e Historiografia, v. 7, n. 2, p. 189-209, 2016.

BERNAL, M. Black Athena: the afroasiatic roots of classical civilization. New Brunswick: Rutgers, 1987.

BRAUDEL, F. O Mediterrâneo e o mundo mediterrâneo na época de Filipe II. São Paulo: Martins Fontes, 1983.

BROODBANK, C. The making of the Middle Sea: a history of the Mediterranean from the beginning to the emergence of the Classical World. London: Thames and Hudson, 2013.

CAMPOREALE, G. Variations Étrusques archaïques sur le thême d'Héraclès e le Lion. In: GAULTIER, F.; BRINQUEL, D. (Éd.). Les Étrusques: les plux religieux des hommes. Paris: La Documentations Française, 1997.

GUARINELLO, N. L. História Antiga. São Paulo: Contexto, 2013.

GUARINELLO, N. L. Uma morfologia da História: as formas da História Antiga. Politeia: História e Sociedade, v. 3, n. 1, p. 41-61, 2003.

HORDEN, P.; PURCELL, N. The corrupting sea: a study of Mediterranean history. Malden: Wiley-Blackwell, 2000.

KNAPPETT, C. An Archaeology of interaction: network perspectives in material culture and society. Oxford: Oxford University Press, 2011.

LAVAUD, L. L'image. Paris: Flammarion, 1999.

LIMA, A. C. C. A pólis e suas imagens: produção, circulação e "censura". In: LIMA, A. C. C. (Org.). Pintura e imagem: representações do Mundo Antigo. Rio de Janeiro: Apicuri, 2011.

MALKIN, I. (Ed.) Mediterranean paradigms and Classical Antiquity. London: Routledge, 2005.

MALKIN, I. A small Greek World: networks in the ancient Mediterranean. Oxford: Oxford University Press, 2011.

MORALES, F. A. Cidades invisíveis: para uma crítica do conceito de polis. Archai: Revista de Estudos sobre as Origens do Pensamento Ocidental, v. 4, p. 71-82, 2010. 
MORALES, F. A.; SILVA, U. G. História Antiga e História Global: afluentes e confluências. Revista Brasileira de História, v. 40, n. 83, p. 125-150, 2020.

ROGERS, G. M.; LEFKOWITZ, M. R. Black Athena Revisited. Chapel Hill: University of North Carolina Press, 1996.

SCHNAPP, A. De la cité des images à la cité dans l'image. METIS. Revue d'Anthropologie du Monde Grec Ancien, v. IX-X, p. 209-218, 1994-1995.

SILVA, G. J. História antiga e usos do passado: um estudo de apropriações da Antiguidade sob o regime de Vichy (1940-1944). São Paulo: Annablume, 2007. YOUNG, R. White mythologies: writing history and the West. Hove: Psychology Press, 2004. 